\title{
A high-content imaging assay for the quantification of the Burkholderia pseudomallei induced multinucleated giant cell (MNGC) phenotype in murine macrophages
}

\author{
Gianluca Pegoraro ${ }^{1,2,3}$, Brett P Eaton ${ }^{1}$, Ricky L Ulrich', Douglas J Lane ${ }^{1}$, Jenifer F Ojeda', Sina Bavari ${ }^{1}$,
} David DeShazer ${ }^{1}$ and Rekha G Panchal ${ }^{1 *}$

\begin{abstract}
Background: Burkholderia pseudomallei (Bp), a Gram-negative, motile, facultative intracellular bacterium is the causative agent of melioidosis in humans and animals. The Bp genome encodes a repertoire of virulence factors, including the cluster 3 type III secretion system (T3SS-3), the cluster 1 type VI secretion system (T6SS-1), and the intracellular motility protein BimA, that enable the pathogen to invade both phagocytic and non-phagocytic cells. A unique hallmark of Bp infection both in vitro and in vivo is its ability to induce cell-to-cell fusion of macrophages to form multinucleated giant cells (MNGCs), which to date are semi-quantitatively reported following visual inspection.

Results: In this study we report the development of an automated high-content image acquisition and analysis assay to quantitate the Bp induced MNGC phenotype. Validation of the assay was performed using T6SS-1 ( $\Delta$ hcp 1) and T3SS-3 ( $\triangle b s a Z)$ mutants of Bp that have been previously reported to exhibit defects in their ability to induce MNGCs. Finally, screening of a focused small molecule library identified several Histone Deacetylase (HDAC) inhibitors that inhibited Bp-induced MNGC formation of macrophages.

Conclusions: We have successfully developed an automated $\mathrm{HCl}$ assay to quantitate MNGCs induced by Bp in macrophages. This assay was then used to characterize the phenotype of the Bp mutants for their ability to induce MNGC formation and identify small molecules that interfere with this process. Successful application of chemical genetics and functional reverse genetics siRNA approaches in the MNGC assay will help gain a better understanding of the molecular targets and cellular mechanisms responsible for the MNGC phenotype induced by Bp, by other bacteria such as Mycobacterium tuberculosis, or by exogenously added cytokines.
\end{abstract}

Keywords: Burkholderia pseudomallei, High Content imaging, phagocytosis, Multinucleated giant cells, Macrophages

\section{Background}

Burkholderia pseudomallei (Bp) is a Gram-negative bacterial pathogen and the causative agent of melioidosis, a potentially fatal disease if misdiagnosed or left untreated $[1,2]$. Bp is endemic to Southeast Asia, Northern Australia, South America, Africa, Middle East, China and India and the pathogen can be commonly isolated from soil and surface waters $[1,3,4]$. Both acute and chronic infections

\footnotetext{
* Correspondence: rekha.g.panchal.civ@mail.mil

'Molecular and Translational Sciences Division, United States Army Medical Research Institute of Infectious Diseases, 1425 Porter Street, Fort Detrick,

Frederick, MD 21702-5011, USA

Full list of author information is available at the end of the article
}

with $\mathrm{Bp}$ can be acquired by inhalation, percutaneous inoculation and in rare circumstances by ingestion. The clinical symptoms of melioidosis are broad and may present as acute or chronic pneumonia, internal organ abscesses (lung, liver and spleen), fulminating septicemia and uncommonly individuals can be asymptomatic [1]. In fact, and due to the facultative intracellular lifestyle of $\mathrm{Bp}$, dormant cases have been reported with the most notable being 62 years after initial exposure [5]. With the relative ease of genetic manipulation, environmental availability and intrinsic antibiotic resistance, Bp is listed as a category B select agent by the U.S. Centers for Disease Control and Prevention [6]. 
Macrophages and monocytes play critical roles in both the innate and adaptive arms of the immune system and are the first line of host defense mediating immunological responses to foreign antigens [7,8]. These cells have diverse functions within the host including phagocytosis of bacterial, fungal, parasitic and viral pathogens, cytokine and chemokine biosynthesis for inflammatory mediated responses to invading pathogens as well as regulation of cellular metabolic processes including fatty acid metabolism, iron reprocessing and mineral reabsorption [9-11]. In response to certain biological triggers, monocytes or macrophages form multinucleated giant cells (MNGCs), which involves the fusion of adjacent cells and results in a multinucleated cell with a single cytoplasmic compartment [12]. MNGCs are a well characterized phenotype in tissue granuloma formation in response to bacterial infection, with the most notable being associated with Mycobacterium tuberculosis (Mtb). Using various animal, human, in vitro cell culture and explant tissue models of Mtb infection it has been demonstrated that monocytes develop into various MNGC types, which is essential in the confinement of Mtb within infectious granulomas [13-20]. Likewise, monocyte and macrophage MNGC formation can be induced in vitro using various conditioned mediums containing exogenous cytokines, lectin, phorbol myristate acetate and even select antibodies [21-32]. The most notable cytokines associated with monocyte and macrophage differentiation into MNGCs are Interleukin-4 (IL-4) and Interferon gamma (IFN- $\gamma$ ). However, recent reports have also demonstrated that MNGC formation is dependent on diverse range of cellular proteins including CD36, TREM-2, E-cadherin, CCL2 and Rac1, MMP9, DCSTAMP, E-cadherin and Syk; all of which are involved in intracellular signaling, cell surface communication, proteolysis, chemotaxis and cellular transcription [28,33-43].

A unique phenotypic characteristic of Bp infection, in addition to Burkholderia mallei (Bm) and Burkholderia thailandensis (Bt), is the ability to induce host cell MNGC formation following cellular uptake, in both tissue culture cells (i.e. murine macrophages) and in primary human cells (patients with active melioidosis) [44-47]. MNGC formation has been demonstrated in both phagocytic and non-phagocytic cells in addition to patient tissue(s) with active melioidosis [46-54]. The importance of Bp-mediated MNGC formation during infection is currently unknown, but it is possible that cell to cell spread via MNGC allows the pathogen to avoid immune surveillance in vivo. The $\mathrm{Bp}$ genome encodes a diverse range of specialized protein secretion systems including three type III secretion systems (T3SS) and six type VI secretion systems (T6SS) $[1,55,56]$. Mutation of the Bp T3SS-3, which is homologous to the Shigella Mxi-Spa and Salmonella SPI1 T3SSs, results in loss of Bp induced MNGC formation, inability of endosomal escape and loss of virulence in animal models of Bp infection [50,53,57]. Likewise, disruption of components making up the T6SS-1 reduced animal virulence and hindered MNGC formation in RAW264 macrophages [58]. In addition, it has been shown that the Bp alternative sigma factor RpoS, which is involved in genome-wide regulation of bacterial adaptation to environmental stress (i.e. nutrient limitation), plays a role in Bp induced MNGC formation [59]. Recently, the molecular mechanism of Bp MNGC formation was revealed by Toesca et al. [60]. The T6SS-1 valine-glycine repeat tail spike protein (VgrG1) possesses a novel fusogenic domain at its $\mathrm{C}$-terminus that mediates cell fusion and allows $\mathrm{Bp}$ cell to cell spread.

Automated high content imaging ( $\mathrm{HCI}$ ) microscopy is a powerful technique to quantitatively characterize cellular phenotypes at the single cell level in response to bacterial and viral infection, exposure to drug agonists and antagonists and for drug mechanism of action determination [61-69]. This work describes the development of a cellbased $\mathrm{HCI}$ immunofluorescence assay to quantitatively characterize the MNGC phenotype induced in murine macrophages upon infection with Bp K96243. As a proof of principle for its applicability in a relevant biological setting, this assay was validated using mutants of Bp that were previously described to be defective for MNGC formation in mouse macrophages [58,70]. Furthermore, we used the MNGC HCI assay to screen a focused small molecule library to identify compounds that interfere with MNGC formation induced by Bp. Together, the results of these experiments indicated that the HCI MNGC assay can be used in a medium-throughput format to identify and characterize Bp mutants that are defective in their ability to induce MNGCs and to identify small molecules that inhibit this phenotype.

\section{Results \& discussion \\ Optimization of the MNGC assay}

To develop an automated high-throughput method for quantitating MNGCs, RAW264.7 macrophages were either not infected (Figure 1A, Top panel-mock) or infected at an MOI of 30 with wild-type Bp K96243 (Figure 1A, bottom panel-wild-type Bp). After $2 \mathrm{~h}$ excess extracellular bacteria were then eliminated by sequential washes in PBS and cells were further incubated in medium containing kanamycin. At $10 \mathrm{~h}$ post-infection macrophages were first fixed, and then immunofluorescence (IF) staining was performed to detect bacteria and cellular structures. Finally, samples were imaged by high-throughput confocal fluorescence microscopy. Cell nuclei were stained with the DNA dye Hoechst 33342 and the cell body with the CellMask DeepRed dye. Bacteria associated with or internalized by macrophages were detected by staining cells with an antiBurkholderia pseudomallei monoclonal antibody. 

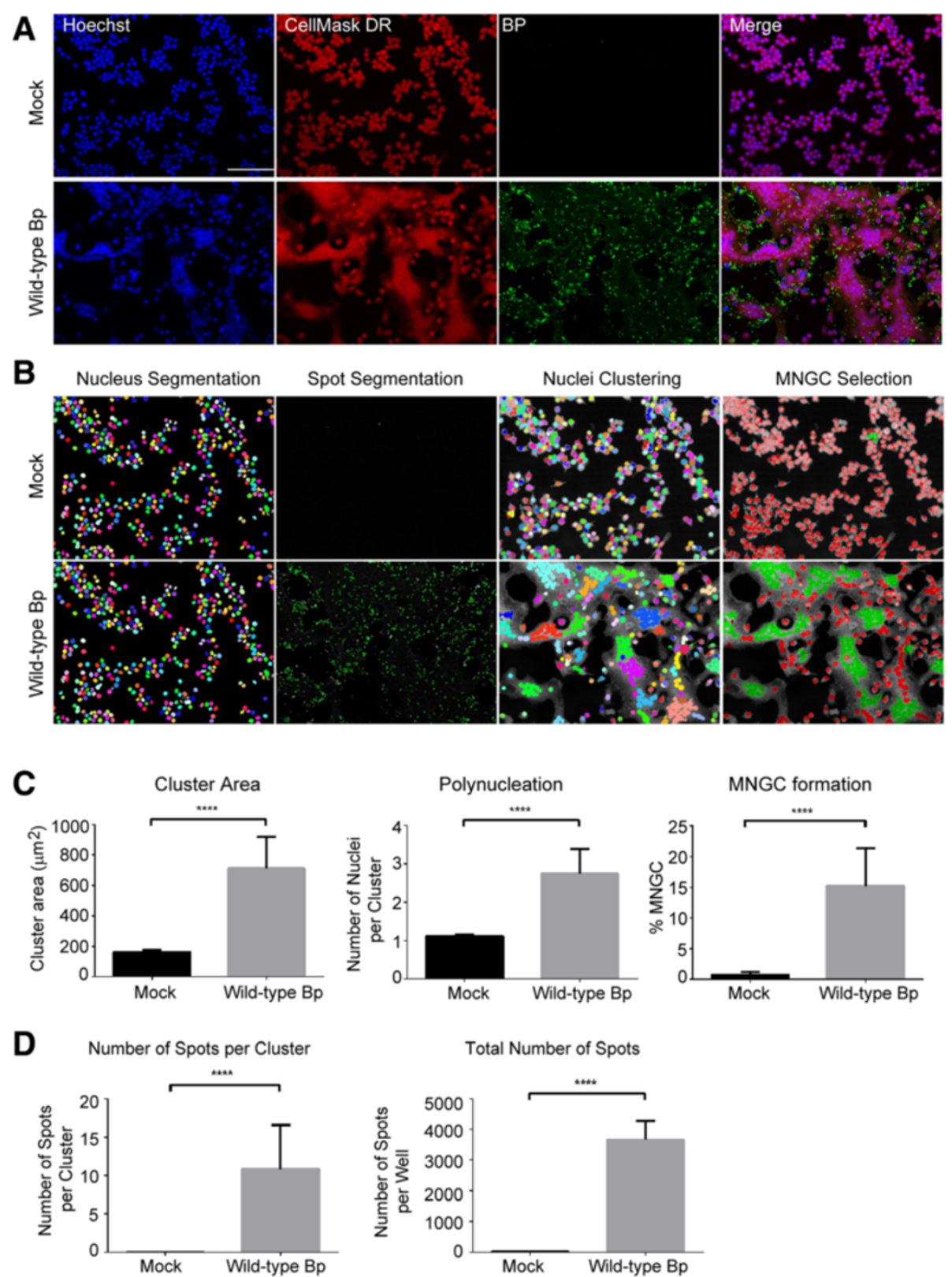

Figure 1 Quantitative analysis of B. pseudomallei K96243 induced murine macrophage MNGC formation. (A) Representative 20X magnification confocal images of RAW264.7 macrophages that were not infected (mock) or infected with wild-type B. pseudomallei K96243 at a MOl of 30 at $10 \mathrm{~h}$ post-infection. Images of cell nuclei (stained with the Hoechst 33342 dye), cell cytoplasm (stained with CellMaskDR-CellMask DeepRed) and Bp: bacteria labeled using an anti-B. pseudomallei mouse monoclonal and a secondary anti-mouse/Alexa488 antibody. Scale bar: $90 \mu$ m. (B) Visual representation of the MNGC Image Analysis procedure. Each object (Nuclei) is pseudocolored with a unique color in the nucleus segmentation panel. Bacterial spots are pseudocolored in green in the spot segmentation panel. Nuclei clustering: Nuclei are clustered based on distance as described in Experimental procedures to generate the Cluster population. In the MNGC selection panel, image objects classified as MNGC are pseudocolored in green, and non-MNGC objects are pseudocolored in red. (C) Histograms representing the quantification of cellular attributes of the cluster population as measured by the MNGC image analysis procedure described in Figure 1B. (D) Histograms showing the results of the quantification of cellular attributes related to bacterial spot formation. In $\mathbf{C}$ and D means +/- standard deviation (SD) are shown for three independent B. pseudomallei macrophage infections performed on separate days and with six replicates/plate. $n=18$ and $>500$ nuclei were analyzed per well. ${ }^{* * *} p<0.0001$.

As observed in the fluorescence microscopy images, Bp infection induced cell-to-cell fusion, clustering of the nuclei and cell body enlargement in a substantial fraction of infected macrophages when compared to mock infected samples (Figure 1A). These cellular objects fit the definition of MNGC. A large number of Bp bacterial spots were found to be either internalized or in close proximity with the boundaries of infected cell bodies. In 
these experimental conditions not all the infected cells appear to be part of an MNGC object (Figure 1A). Hence, it was important to develop an $\mathrm{HCI}$ analysis that would recognize and distinguish MNGC objects from nonMNGC objects in a heterogeneous population of infected cells. To address this issue, we took advantage of the close proximity of the nuclei in MNGC's to recognize and classify MNGC clusters. Briefly, and as shown in Figure 1B, cell nuclei were first identified by using the Hoechst 33342 channel image, thus obtaining a population of objects that was named "Nuclei". The cell body edges were identified by expanding the body of the nucleus detected in the previous step. The cell body borders were then detected by using the CellMask DeepRed channel image.

Bp spots were identified using the Bp antibody channel image. Several cellular attributes were calculated for the Nuclei population, the most relevant being: number of objects, cell body area and number of bacterial spots per object. The next step in the image analysis consisted in recursively clustering distinct Nuclei objects together into a single "Cluster" object, provided that their nuclei were either touching or adjacent. All the cellular attributes of the Nuclei population calculated on a single-object basis were then summed into the corresponding Cluster object. In addition, the number of Nuclei per Cluster (Polynucleation) was calculated. Finally, based on visual inspection of images analyzed with this strategy, the Cluster population was further classified into either MNGC (>3 Nuclei per Cluster) or non-MNGC ( $\leq 3$ Nuclei per Cluster) sub-populations (Figure 1B). This approach was then used to quantitatively measure MNGC formation in RAW264.7 macrophages infected with wild-type Bp K96243. As seen in Figure 1C, the results of these experiments indicate that the HCI MNGC analysis can be used at the well level to detect MNGC formation in Bp K96243-infected populations when compared to mock infected samples. In particular, and as expected, infected cells had a 4.3-fold increase in Cluster Area, a 2.4-fold increase in Number of Nuclei per Cluster, and a 21-fold increase in the Percentage of MNGC when compared to non-infected samples.

\section{Single cell analysis of the Bp K96243 infected macrophages}

Quantitation of MNGCs using the image analysis procedure typically outputs statistical descriptors, such as means and standard deviations, at the well level. While the well level analysis of MNGC formation provides statistically significant differences between mock infected and Bp K96243 infected cells (Figure 1B), we also wanted to determine if our image analysis approach was capable of distinguishing MNGCs in heterogeneous populations of infected cells. To test this, we plotted single-cell data generated by the MNGC analysis on either mock-infected or Bp K96243 infected cells (Figure 2). As expected, using a similar classification approach to the one described above, we were able to visually detect an increase in the incidence of MNGC formation in images from Bp K96243 infected macrophages compared to uninfected macrophages (Figure 2A). The percentage of Cluster objects classified as MNGC (+) increased from $0.52 \%$ (mock) to $6.6 \%$ (Bp K96243) (Figure 2B). The presence of a small percentage of MNGC $(+)$ objects in uninfected RAW264.7 samples reflects the presence of cell clumps morphologically unrelated to real MNGC (Figure 2A and Figure $2 \mathrm{~B}$ ) and constitutes the negative control measurement background in the MNGC analysis. Nevertheless, as expected, clusters classified as MNGC (+) in Bp K96243 infected samples had larger mean Cluster Area and a larger mean Number of Spots per Cluster when compared to the MNGC (-) objects present in the same samples at the $10 \mathrm{~h}$ time point. Accordingly, the higher incidence of MNGC (+) objects in Bp K96243 infected cells when compared to mock infected cells led to a shift towards higher values of Cluster Area and Number of Spots per Cluster in the single-cell distributions (Figure 2C). Thus, the results of the MNGC HCI analysis indicate that, at an MOI of 30 and $10 \mathrm{~h}$ post Bp K96243 infections, there are at least two sub-populations of RAW264.7 cells associated with bacterial spots, which are phenotypically dissimilar, both in terms of cell size and polynucleation (Figure $2 \mathrm{~B}$ and Figure $2 \mathrm{C}$ ).

\section{Validation of the MNGC assay to detect mutants defective in their ability to induce MNGC}

Having shown that the HCI MNGC assay is capable of detecting and quantitating $\mathrm{Bp}$ induced cell-to-cell fusion, we then set out to test whether this method could be used to detect defects in MNGC formation caused by mutations in $\mathrm{Bp}$ genes. It was previously reported that deletion of the Bp $\Delta h c p 1$ gene, which is encoded within the cluster 1 type VI secretion system operon, resulted in a significant increase in the $50 \%$ lethal dose in a Syrian hamster model of infection $\left(10^{3}\right.$ vs. $<10$ bacteria), in reduced macrophage intracellular replication and most notably in the failure to induce macrophage MNGC formation [58]. Likewise, it was demonstrated that deletion or inactivation of the Bp $b s a Z$ gene, which is encoded within the Bp T3SS-3 results in delayed macrophage vacuolar escape, in reduced intracellular replication at 3,6 , and $12 \mathrm{~h}$ and in sporadic MNGC formation [50]. Thus, in order to test the possibility of using the HCI MNGC assay to profile Bp mutants, we analyzed the ability of Bp K96243 and the two isogenic mutants harboring gene deletions in the Bp T6SS-1 ( $\Delta h c p 1)$ and the T3SS-3 $(\Delta b s a Z)$ to induce MNGC formation at two different time points. RAW264.7 macrophages were not infected (mock), infected with wild-type Bp K96243 or with the $\Delta h c p 1$ or $\Delta b s a Z$ mutants at a MOI of 30 for $2 \mathrm{~h}$ and then processed in IF and HCI as described 

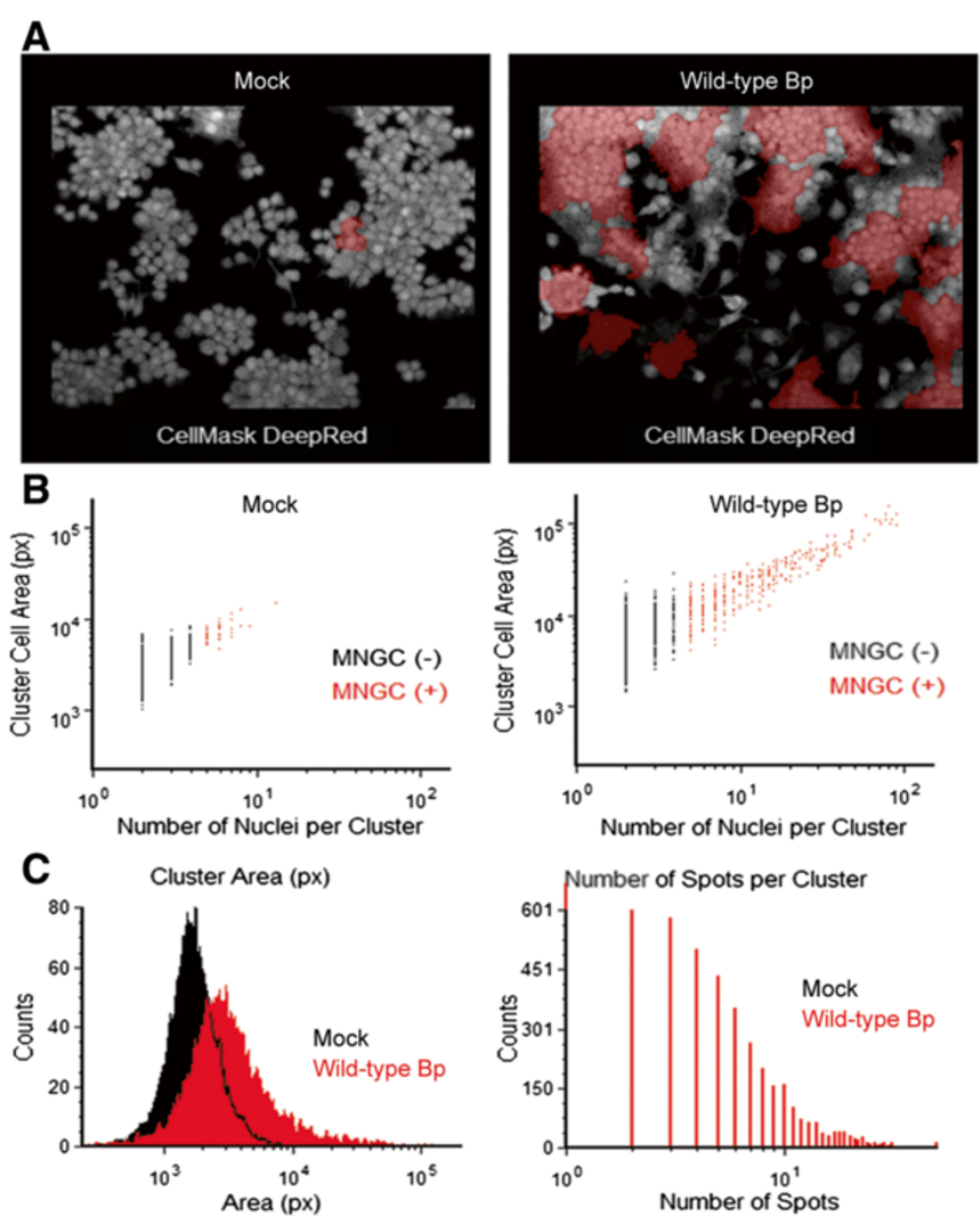

Figure 2 Single cell analysis of B. pseudomallei K96243 induced murine macrophage MNGC formation. (A) Representative 20X magnification confocal images of RAW264.7 macrophages that were not infected (Mock) or infected with wild-type B. pseudomallei K96243 at a MOl of 30 at $10 \mathrm{~h}$ post-infection. CellMask DeepRed -cytoplasmic/nuclear stain. (B) Single cell image cytometry analysis of MNGCs induced in macrophages that were not infected (Mock; left panel) or infected with wild-type B. pseudomallei K96234 (right panel). Objects classified as MNGC (+) are pseudocolored in red in the image plots and in the dot plot graphs. (C) Histogram plots showing the distribution of the cluster populations based on the cluster area (left panel) in macrophages that were uninfected (Mock, black) or infected with wild-type B. pseudomallei K96234 (Wild-type Bp, red); and the number of bacterial spots associated with each cluster (right panel).

above (Figure 3). At the early time point $(2 \mathrm{~h})$, infection with all the three Bp strains led to the appearance of bacterial foci either in the cytoplasm or associated with the cell membrane of RAW264.7 macrophages (Figure 3A). When quantified with the MNGC analysis pipeline we could detect significant differences between the Bp K96243 (wt) and the mock infected samples in terms of mean Number of Spots per Clusters, Cluster Area and marginally significant differences in terms of mean Percentage of MNGC (Figure 3B). Bp $\Delta h c p 1$ had a significantly lower Number of Spots per Clusters and a significantly lower total Number of Spots when compared to Bp K96243 (wt) (Figure $3 \mathrm{C}$ ). At this time point, $\mathrm{Bp} \Delta b s a Z$ was indistinguishable from Bp K96243 (wt) (Figure 3C). Altogether the results of these experiments indicate that deletion of $b s a Z$ has no effect on bacterial adhesion and/or uptake by
RAW264.7 cells, while deletion of $\Delta h c p 1$ has some minor but significant effects on these processes. Our observed results for the Bp $\Delta b s a Z$ mutant were similar to that reported by French et al. [44]. On the contrary, our findings with Bp $\Delta h c p 1$ mutant during this early infection time did not correlate with those reported [44,58], which may due to the differences in the experimental conditions such as MOI, time of infection or the type of Burkholderia strain used in the studies.

At later stages of the bacterial replication cycle $(10 \mathrm{~h}$ post-infection), more significant differences were observed between Bp K96243 (wt) and the mutant strains (Figure 4). Of note, the bacterial mutants showed more diffused $(\Delta h c p 1)$ or rounder, reduced and more isolated spot staining pattern $(\triangle b s a Z)$ when compared to $\mathrm{Bp}$ K96243 (wt) (Figure 4A, Bp panels). As expected, Bp 


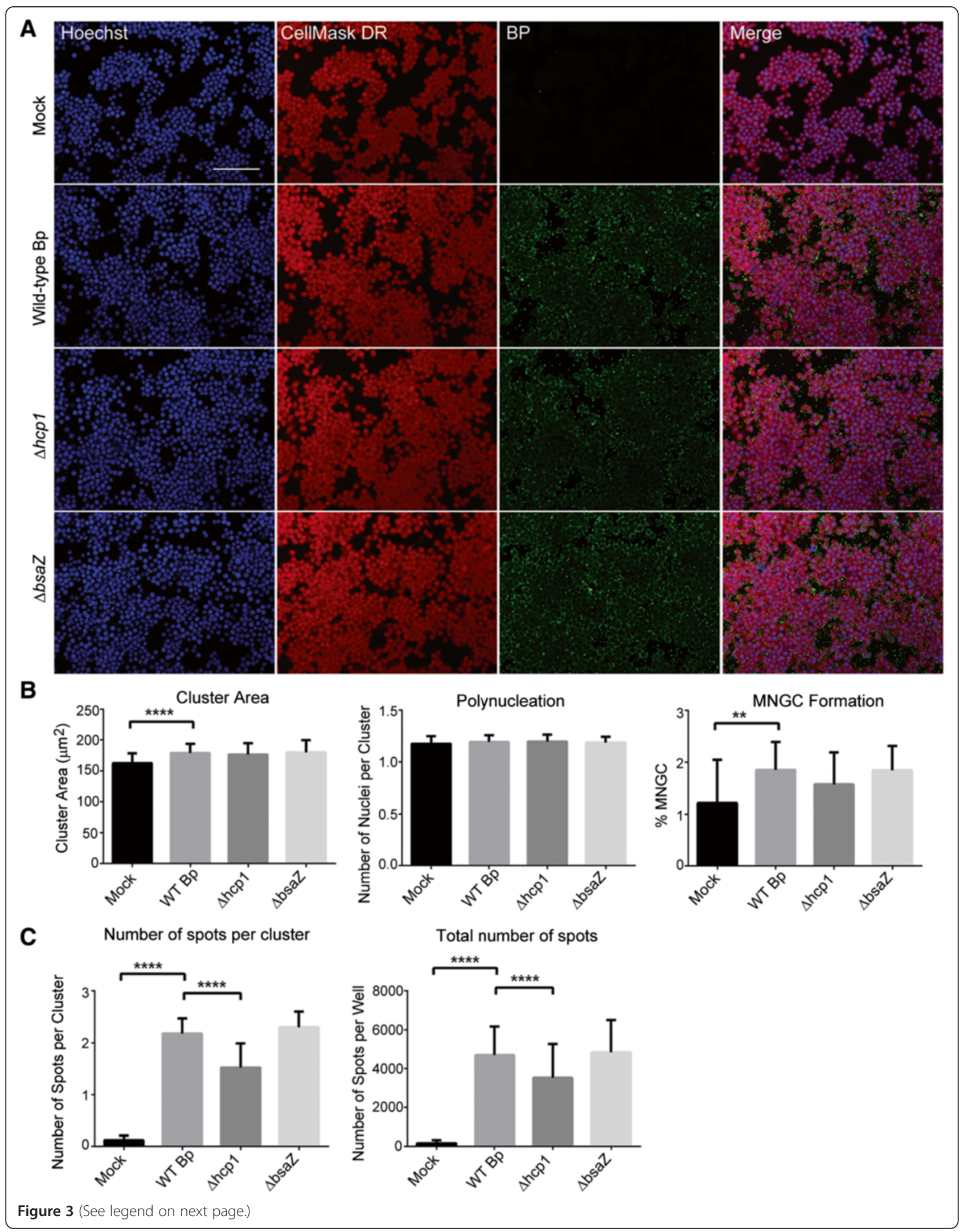



$\mathrm{MOI}$ with wild-type Bp K96243 (wt), or Bp $\Delta$ hcp 1, or Bp $\Delta b s a Z$ respectively. Scale bar: $90 \mu \mathrm{m}$. Macrophages were infected with Bp for $2 \mathrm{~h}$ and then fixed, processed in IF and images were acquired and analyzed according to the MNGC analysis script (described in the Methods - Image acquisition and analysis section and shown in Figure 1B). (B) Bar graphs for the quantification of several cellular features of MNGC formation. (C) Bar graphs for the quantification of bacterial spots per MNGC cluster and total number of bacterial spots. In $\mathbf{B}$ and $\mathbf{C}$ means $+/-$ SD are shown of 6 replicates per plate, 3 plates run on independent days $(n=18)$. For each replicate well $>1000$ nuclei were analyzed. ${ }^{* * *} p<0.0001 ;{ }^{* *} p<0.01$.

K96243 (wt) infection strongly induced MNGC formation, while in this respect both $\mathrm{Bp} \Delta b s a Z$ and $\mathrm{Bp} \Delta h c p 1$ were defective (Figure 4A, Hoechst and CellMask DR panels). HCI analysis was used to quantify differences between Bp K96243 (wt) and the bacterial mutant strains in their potential to induce the MNGC phenotype in infected RAW264.7 macrophages (Figure 4B and Figure 4C). In these experimental conditions Bp K96243 (wt) induced a 2-fold increase in mean Cluster Area and mean Number of Nuclei per Cluster and a 4-fold increase in mean Percentage of MNGC when compared to the negative control (Figure 4B). All these differences were statistically significant. On the contrary, using the same experimental conditions, while bacterial spots were still detected in IF (Mean Total Number of Spots per well, Figure $4 \mathrm{C}), \mathrm{Bp} \Delta h c p 1$ or Bp $\Delta$ bsaZ failed to induce an increase in the mean Cluster Area, Number of Nuclei per Cluster or Percentage MNGC and were hardly distinguishable from the uninfected samples (Figure 4B). Significant differences in the mean number of Spots per Cluster between Bp K96243 (wt) and Bp $\Delta h c p 1$ or Bp $\triangle b s a Z$ were observed (Figure $4 C$ ) and were probably due at least in part to an increase in the mean Cluster Area in Bp K96243 infected samples (see above). The inability to see an increase in the total number of bacterial spots during the intracellular replication step $(10 \mathrm{~h}$ postinfection) compared to early uptake or phagocytosis step ( $2 \mathrm{~h}$ post-infection) may partly be due to the killing of the internalized bacteria by the professional phagocytes. Although bacteria can be detected and quantitated by $\mathrm{HCI}$, this technique it does not measure bacterial viability. Altogether, these results show that the HCI MNGC assay can be implemented to quantitatively characterize mutant Bp strains phenotype based on cellular morphological changes induced in infected host cells. Furthermore, our HCI results regarding reduced MNGCs and bacterial spots following infection with Bp $\Delta h c p 1$ or Bp $\Delta b s a Z$ mutants compared to wild type $\mathrm{Bp}$ at $10 \mathrm{~h}$ post-infection are consistent with previously published data $[44,58]$.

\section{Screening of a small molecule library in the MNGC assay}

To discover possible cellular pathways that are hijacked by $\mathrm{Bp}$ and that might regulate cell-to-cell fusion, we used the HCI MNGC assay to screen a small, functionally focused collection of 43 compounds in duplicate. The compounds in this collection are annotated as targeting pathways involved in the epigenetic regulation of chromatin (See Experimental procedures for details). Bacterial infection induced epigenetic changes such as histone modifications, DNA methylation, chromatin remodeling, which in turn affect host cell signaling has been shown to either promote host defense or increase susceptibility to infection [71]. To investigate Bp induced epigenetic changes which in turn may modulate MNGC formation, RAW264.7 macrophages were first pre-treated with the compound library and then infected with Bp K96243. Cells treated with DMSO (Vehicle) and infected with Bp K96243 were considered as negative controls. At $8 \mathrm{~h}$ post-infection cells were fixed and processed in IF for the HCI MNGC assay as described above. Representative images of macrophages that were not infected (mock) or infected with Bp K96243 in presence of DMSO or identified hit compounds are shown in Figure 5A. Compounds were ranked based on the Z-score for the Percentage of MNGC attribute (Figure 5B). Compounds with high Z-scores were inhibitors of Bp K96243 induced MNGC formation, whereas compounds with low Z-scores increased MNGC formation. Compounds that had a percentage of MNGC Z-score $>3$ were scored as positive hits. A total of 15 out of the original 43 compounds matched this criterion (Figure 5B). Furthermore, to exclude cytotoxicity as the leading mechanism of action for MNGC reduction, compounds that had a Number of Nuclei Z-score $<-3$ were not considered for further analysis. A total of 9 out of the original 15 compounds passed the cytotoxicity filter (Figure $5 \mathrm{~B}$ ) and were considered as hits. A total of 7 out of the 9 identified hits belong to the Histone Deacetylase (HDAC) enzyme inhibitor category. Importantly, none of these hit compounds reduced the total number of Bp spots per well (Data not shown), ruling out that their mechanism of action involves direct inhibition of bacterial adhesion and/or uptake by host cells. Visual inspection of samples treated with the three HDAC inhibitors (Scriptaid, Fluoro-SAHA, and M-344) confirmed that these compounds were not cytotoxic and hence did not alter the cell number when compared to DMSO treated samples, but substantially inhibited MNGC formation in their presence. Furthermore, M-344 showed a dose-dependent inhibition of MNGC formation induced upon Bp K96243 infection (Figure 5C). Altogether, these results indicate that the HCI MNGC assay can be used to screen small molecule libraries for the identification of compounds that can inhibit MNGC formation and that 


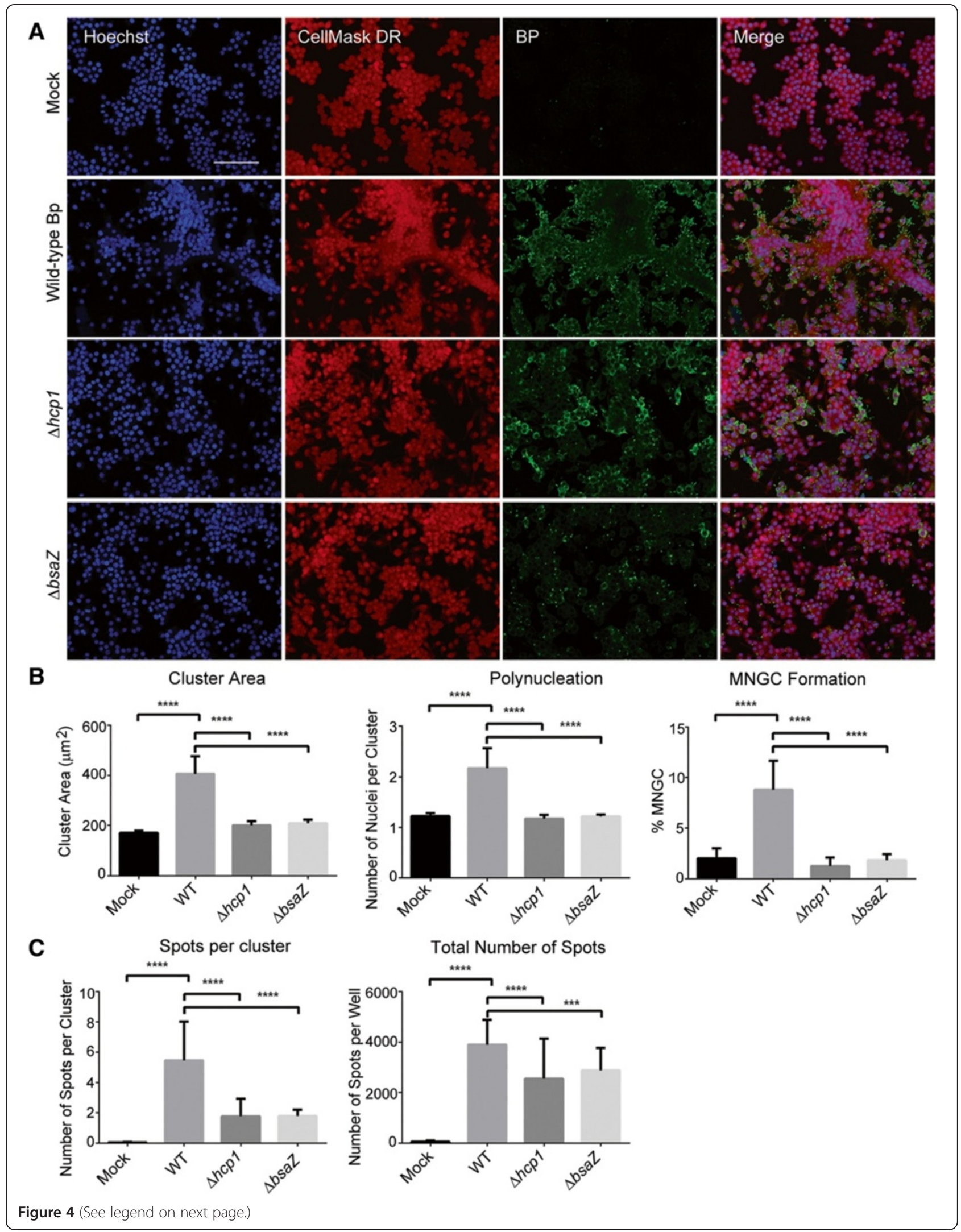


one or more HDAC's might be involved in the positive regulation of this process.

\section{Conclusions}

In summary, we have successfully developed an automated $\mathrm{HCI}$ assay to quantitate MNGCs induced by Bp in macrophages. This assay was then used to characterize the phenotype of the $\mathrm{Bp}$ mutants for their ability to induce MNGC formation and identify small molecules that interfere with this process. This assay can also be applied to identify the molecular targets and mechanisms responsible for the $\mathrm{Bp}$ induced phenotype, which to date are poorly understood. In addition, this assay has potential application for characterizing bacterial isolates as well as the identification of immune modulators such as cytokines that induce or inhibit this phenotype. Currently, we are not aware of a robust and direct $\mathrm{HCI}$ method to unambiguously distinguish cell clumps from MNGC. Nevertheless, in the experimental conditions described in the manuscript, and in the absence of tested compounds, the detection of MNGC via our HCI method is clearly dependent on infection by Bp (Figures 1, 4 and 5). Compounds that induce cell clumping rather than MNGC-formation might be counter-screened by measuring MNGC formation in mock infected/compound treated cells. In addition, it will be of future interest to develop and implement calculated cellular attributes (such as Cell Area) or the IF staining of additional cellular structures (such as Actin or Tubulin) to further refine and improve the $\mathrm{HCI}$ analysis of MNGC.

\section{Experimental procedures}

\section{Bacterial propagation}

Burkholderia pseudomallei K96243 was maintained in either Luria-Bertani (LB) broth, on LB plates or on $1.5 \%$ agar plates containing 5\% sheep blood (SBA). Broth cultures were grown at $37^{\circ} \mathrm{C}$ with shaking at $250 \mathrm{rpm}$ and agar plates were incubated at $37^{\circ} \mathrm{C}$. For macrophage infections, Bp was grown on $\mathrm{LB}$ plates for $\sim 18 \mathrm{~h}$ at $37^{\circ} \mathrm{C}$ and a loopful of the culture was suspended in $10 \mathrm{ml}$ of Dulbecco's Modified Eagle Medium (DMEM) (Gibco, Carlsbad, CA). Bacterial concentrations were determined by measuring the $\mathrm{OD}_{600}$ and cell suspensions were adjusted to a multiplicity of infection (MOI) of 30 using a conversion factor of $5 \times 10^{8} \mathrm{CFU} / \mathrm{ml}$ per unit of optical density at $600 \mathrm{~nm}$ [72]. All Bp manipulations were performed in biosafety level 3 laboratories.

\section{Construction of a B. pseudomallei $\Delta b s a Z$ type three secretion mutant}

Genomic DNA from Bp $\Delta$ sctUBp3 [70] was purified [73] and used as template DNA for PCR amplification of the $\triangle b s a Z$ gene. Gene amplification was performed using the forward primer bsaZ-FXb 5'-CATGTCTAGACTTCACGT CACGTCATGCCGAGCGACACG-3' and reverse primer bsaZ-RH 5'-CATGAAGCTTTGTTGGCTAGTGGTCGTT CCC-3' with the Epicentre FailSafe Kit with buffer "D" (Epicentre Technologies, Madison, WI) using the following conditions: one cycle at $94^{\circ} \mathrm{C}$ for $5 \mathrm{~min} ; 30$ cycles at $94^{\circ} \mathrm{C}$ for $30 \mathrm{sec}, 56^{\circ} \mathrm{C}$ for $30 \mathrm{sec}$, and $72^{\circ} \mathrm{C}$ for $1 \mathrm{~min}$; followed by a final 7 min extension at $72^{\circ} \mathrm{C}$. Characters in boldface in the above primer pair represents the $\mathrm{XbaI}$ and HindIII sites incorporated into the oligonucleotides for directional cloning. PCR products were resolved on a $2 \%$ agarose gel and excised using the GeneClean III kit (Qbiogene, Carlsbad, California). Purified PCR fragments were digested with XbaI and HindIII (New England Biolabs, Ipswich, MA) using buffer " 2 ", cleaned as described above and cloned into the similarly digested $s a c B$-based suicide plasmid pMo130 [74] to generate $\mathrm{pMo} \Delta b s a Z$. Ligations were transformed into chemically competent Escherichia coli TOP10 (Invitrogen, Carlsbad, CA) and recombinant plasmids were purified using the Wizard Plus SV miniprep kit (Promega, Madison, WI). pMo $\Delta b s a Z$ was electroporated into E. coli S17-1 and mobilized into Bp K96243 as previously described [75,76]. $\mathrm{pMo} \Delta b s a Z$ was resolved from transconjugants by culturing the isolates in $\mathrm{LB}$ without $\mathrm{NaCl}$ containing $10 \%$ (wt/vol) sucrose for $3-4$ days at $25^{\circ} \mathrm{C}$. Deletion of the $\mathrm{Bp} b s a Z$ gene was confirmed using PCR and apparent by a reduction in the amplicon size of $\sim 1060 \mathrm{bp}$.

\section{Tissue culture and macrophage infections}

The RAW264.7 cell line was maintained in DMEM (Gibco) containing 10\% FBS (Hyclone, Logan, UT), 1\% non-essential amino acids (Sigma, St. Louis, MO), 1\% HEPES buffer (Gibco) and $1 \%$ L-Glutamine at $37^{\circ} \mathrm{C}$ under an atmosphere of $5 \% \mathrm{CO}_{2}$. For macrophage infections, BD Falcon 96-well plates (Franklin Lakes, NJ) were seeded with $\sim 2 \times 10^{4}$ cells/per well and incubated overnight as described above to obtain $\sim 4 \times 10^{4}$ cells/ well. Macrophages were infected with Bp at a MOI of 30 (or otherwise noted) for $2 \mathrm{~h}$, monolayers washed three times with PBS to remove extracellular bacteria and either macrophages were fixed ( $2 \mathrm{~h}$ infection) or prewarmed DMEM containing 10\% fetal bovine serum and $250 \mu \mathrm{g} / \mathrm{ml}$ of kanamycin (Sigma) was added to reduce 


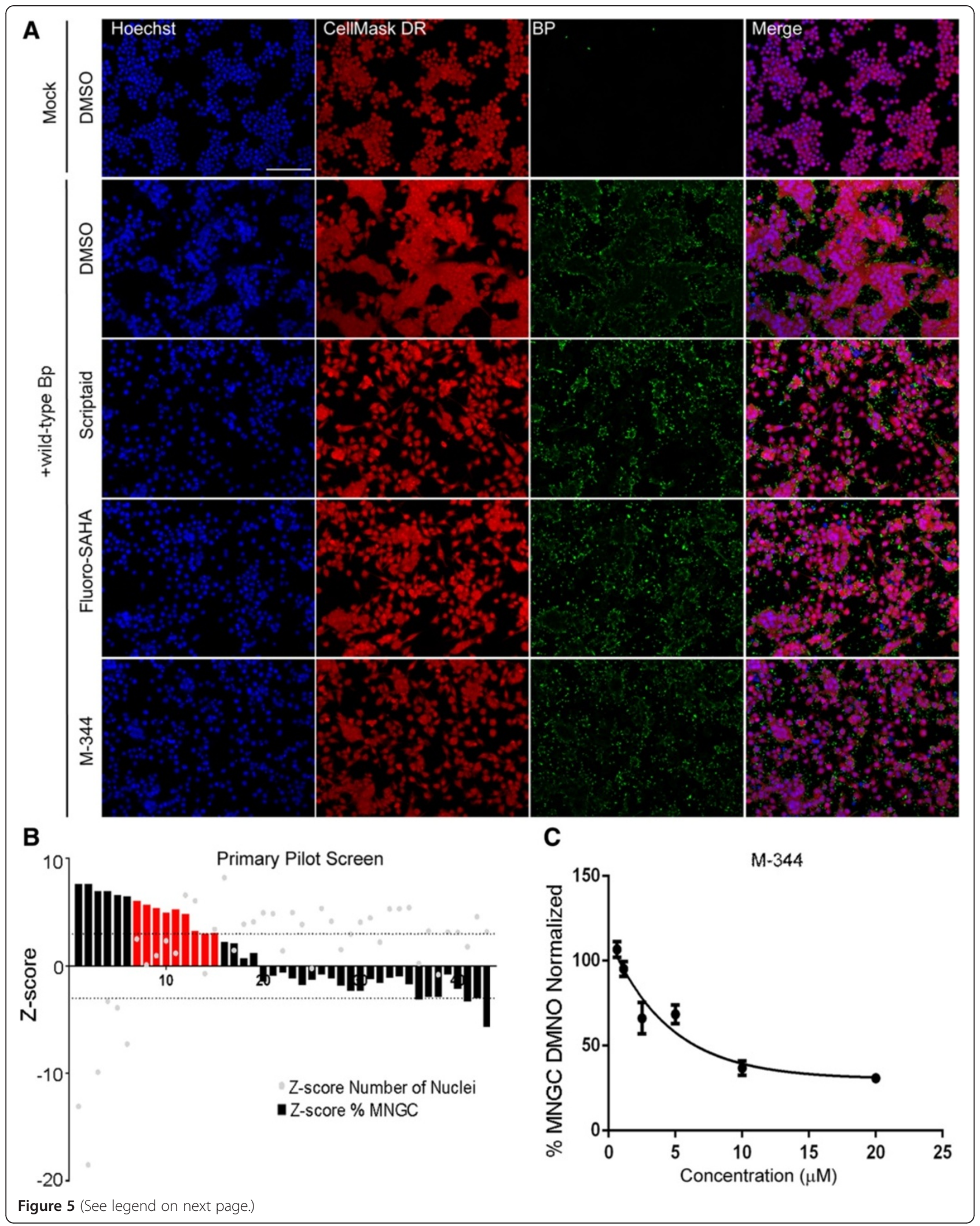


(See figure on previous page.)

Figure 5 Screening of focused small molecule library for inhibitors of MNGC formation. RAW264.7 macrophages were pretreated for $2 \mathrm{~h}$ with a collection of 43 compounds active against enzymes involved in epigenetics regulation at a concentration of $20 \mu \mathrm{M}$ and then infected with $30 \mathrm{MOI}$ of Bp K96243 for $8 \mathrm{~h}$. Cells were fixed, stained in IF and imaged as described above. The effect of the tested compounds on MNGC formation was quantified. Compounds were ranked based on the potency of MNGC inhibition when compared to DMSO-treated, Bp K96243infected samples (Negative control). Cytotoxic (Number of Nuclei Z-score $<-3$ ) were not further considered. (A) Representative confocal images of macrophages pre-treated with DMSO control or primary hit compounds active in the MNGC screen. Scale bar: $90 \mu \mathrm{m}$. (B) Compounds that significantly reduced the number of MNGC when compared to DMSO treated samples (\% MNGC Z-score > 3) were scored as positive hits (red bars). Bars represent means from two replicates. (C) Dose-dependent inhibition of MNGC formation by compound M-344 identified in the primary screen.

extracellular bacterial growth. Infections were continued for an additional $8 \mathrm{~h}$ (or otherwise noted) and monolayers were fixed for $\sim 18-24 \mathrm{~h}$ with $10 \%$ formalin prior to antibody staining.

\section{Macrophage and bacterial staining}

Following macrophage fixation cells were washed and subsequently permeabilized for 15 minutes at room temperature with Cellomics $1 \times$ permeabilization buffer (Halethorpe, MD), washed twice with PBS and blocked (minimum of $1 \mathrm{~h}$ ) with Cellomics $1 \mathrm{x}$ blocking buffer. Following incubation, blocking buffer was removed and replaced with $50 \mu \mathrm{L}$ of a $1: 1000$ dilution of $2 \mathrm{mg} / \mathrm{mL}$ anti-Burkholderia pseudomallei monoclonal antibody (AB-BURK-P-MAB3, Critical Reagents Program, Frederick, $\mathrm{MD})$ for $1 \mathrm{~h}$. Unbound primary antibody was removed by two washes with PBS and a 1:500 dilution of Dylight 488 goat anti-mouse secondary antibody (Fisher Scientific, Waltham, MA) was added at room temperature for $30 \mathrm{~min}$. Cells were washed two additional times with PBS and $1 \times$ CellMask DeepRed (Invitrogen) and 1:10,000 Hoechst nuclear stain (Invitrogen, Carlsbad, CA) were added.

\section{Image acquisition and analysis}

An Opera QEHS confocal system (PerkinElmer, Waltham, MA) was used for high-throughput image acquisition. 4 imaging fields per well were acquired with a $20 \mathrm{X}$ water objective in the Blue (Hoechst 33342), Green (Alexa488) and Far Red (CellMask DeepRed) channels on a single Zplane in 2 sequential exposures. The first exposure utilized the $488 \mathrm{~nm}$ and $640 \mathrm{~nm}$ excitation lasers, the emitted light was first filtered by a 405/488/640 primary dichroic mirror, then collected on separate high resolution CCD cameras through $525 / 35 \mathrm{~nm}$ and $690 / 70 \mathrm{~nm}$ band pass filters, respectively. The second exposure used the $405 \mathrm{~nm}$ and the excitation light was filtered first through a 405/ $561 / 640$ primary dichroic mirror, then through a $568 \mathrm{~nm}$ Detection dichroic mirror and finally through a 450/ $50 \mathrm{~nm}$ band pass filters. Images were imported into Columbus 2.3 database (PerkinElmer) and analyzed with Acapella 2.7 (PerkinElmer). For the MNGC assay, nuclei were first identified using the Hoechst33342 channel image as input, then the cell edges were determined using the CellMask DeepRed channel image, and bacterial spots were detected using the Alexa 488 channel image. The nuclei detection described above generated a first population of objects (Nuclei), for which cellular attributes were calculated (Cell Area, Number of Foci per Cell). Nuclei objects were then clustered together based on the distance of their nuclear bodies (Measured in pixels). Nuclei objects whose nuclear bodies were within a distance of 0 or 1 pixels, depending on the experiment, were considered as part of a single Cluster object. All the cellular attributes of the Nuclei population were then imported (As sums) into the corresponding Clusters and the number of Nuclei per Cluster attribute was also calculated. Clusters were then further classified into a MNGC subpopulation based on the number of nuclei present in the cluster (Nuclei per Cluster $>3)$. The Percentage of MNGC was calculated as (Number of MNGC objects)/(Number of Cluster objects)*100. Values in the histograms represent the mean + /SD of 6 replicates on the same plate run on 3 separate days $(n=18)$. Statistical significance for differences in cellular and bacterial attributes between different samples was calculated using the t-test. For single cell analysis presented in Figure 2, images were directly analyzed after image acquisition with Acapella 2.6, (Using an image analysis strategy similar to the one just described above, Nuclear distance for clustering: 3 pixels) and the image analysis results were imported into FCSExpress4 (Denovo Software, Los Angeles, CA), which was used for single cell image cytometry measurements.

\section{Small molecule screening in the MNGC assay}

RAW264.7 macrophages were seeded as described above. Cells were pre-incubated for $2 \mathrm{~h}$ at a final concentration of $20 \mu \mathrm{M}$ with a collection of 43 compounds selected for their activity on enzymes involved in regulation of chromatin function (Screen-Well Epigenetics Library, version 1.0, Enzo Life Sciences). Cells were then infected with 30 MOI of wild-type Bp K96243. Cells treated with DMSO and infected with Bp K96243 were considered as the negative control; whereas DMSO-treated, mock infected cells were considered as the positive control. Two hours postinfection monolayers were washed three times with PBS to remove extracellular bacteria and pre-warmed DMEM containing $10 \%$ fetal bovine serum, the chemical compounds under testing and $250 \mu \mathrm{g} / \mathrm{ml}$ of kanamycin 
(Sigma) was added to reduce extracellular bacterial growth. Infections were continued for an additional $6 \mathrm{~h}$ and monolayers were fixed for $\sim 18-24 \mathrm{~h}$ with $10 \%$ formalin prior to antibody staining. Cells were IF stained and confocal images were acquired as described above. The MNGC HCI analysis procedure was used to calculate the number of nuclei and the percentage of MNGC. The Zscore for these two cellular attributes was calculated as:

$$
Z-\text { Score }_{i j}=\frac{\left(\text { Sample }_{i j}-\mu N\right)}{\sigma N}
$$

Where: Z-Score ${ }_{i j}=$ Z-Score for well in Row "i" and Column "j", \% Sample S $_{\mathrm{ij}}=$ Cellular attribute value for well in Row "i" and Column "j", $\mu \mathrm{N}=$ Mean of the Cellular attribute for the negative controls on the plate, and $\sigma \mathrm{S}=$ Standard Deviation of Cellular attribute for the negative controls on the plate. Compounds that had both Number of Nuclei Z-Score ${ }_{i j}>-3$ (Cytotoxicity filter) and \% MNGC Z-Score ${ }_{i j}>3$ (Activity filter) were considered as active compounds.

\section{Abbreviations \\ MOl: Multiplicity of infection; $\mathrm{HCl}$ : High content imaging;}

MNGCs: Multinucleated giant cells.

\section{Competing interests}

G. Pegoraro was a PerkinElmer employee.

\section{Authors' contributions}

GP: designed and developed the image acquisition and analysis procedures; $\mathrm{DD}$ constructed the Bp $\triangle b s a Z$ mutant; $\mathrm{BE}, \mathrm{DL}$, JO performed all the experiments, RGP conceived the experimental design and drafted the manuscript; SB, RU and DD provided critical review of the manuscript. All authors contributed to writing the manuscript and read and approved the final version.

\section{Acknowledgements}

We would like to thank Paul Brett and Mary Burtnick for providing pMo $\Delta b s a Z$ and Samuel Dickson for help with statistical analysis. This project was funded by the Department of Defense Chemical Biological Defense Program through the Defense Threat Reduction Agency (DTRA) JSTO-CBS. MEDBIO.02.10.RD.010 (to RGP). We would like to thank Oak Ridge Institute for Science and Engineering for participating in the Postgraduate Research Program at the U.S. Army Medical Research and Materiel Command. Opinions, interpretations, conclusions, and recommendations are those of the authors and are not necessarily endorsed by the U.S. Army, nor does mention of trade names, commercial products, or organizations imply endorsement by the U.S. Government.

\section{Author details}

${ }^{1}$ Molecular and Translational Sciences Division, United States Army Medical Research Institute of Infectious Diseases, 1425 Porter Street, Fort Detrick, Frederick, MD 21702-5011, USA. ²Perkin Elmer, Waltham, MA 02451, USA. ${ }^{3}$ Present Address: Center for Cancer Research, National Cancer Institute/NIH, Bethesda, MD 20892, USA.

Received: 20 December 2013 Accepted: 11 April 2014

Published: 22 April 2014

\section{References}

1. Galyov EE, Brett PJ, DeShazer D: Molecular insights into Burkholderia pseudomallei and Burkholderia mallei pathogenesis. Annu Rev Microbiol 2010, 64:495-517.
2. Sprague LD, Neubauer H: Melioidosis in animals: a review on epizootiology, diagnosis and clinical presentation. J Vet Med B Infect Dis Vet Public Health 2004, 51:305-320.

3. Cheng AC, Currie BJ: Melioidosis: epidemiology, pathophysiology, and management. Clin Microbiol Rev 2005, 18:383-416.

4. White NJ: Melioidosis. Lancet 2003, 361:1715-1722

5. Ngauy V, Lemeshev Y, Sadkowski L, Crawford G: Cutaneous melioidosis in a man who was taken as a prisoner of war by the Japanese during World War II. J Clin Microbiol 2005, 43:970-972.

6. Regulations USCOF: Public Health Security and Bioterrorism Preparedness and Response Act, 107th Congress. In Book Public Health Security and Bioterrorism Preparedness and Response Act, 107th Congress. vol. 42. pp. 107-118. 42nd edition. City: Public Law; 2002:107-118.

7. Hoebe $K$, Janssen $E$, Beutler B: The interface between innate and adaptive immunity. Nat Immunol 2004, 5:971-974.

8. Mackaness GB: The Immunological Basis of Acquired Cellular Resistance. J Exp Med 1964, 120:105-120

9. Chawla A, Nguyen KD, Goh YP: Macrophage-mediated inflammation in metabolic disease. Nat Rev Immunol 2011, 11:738-749.

10. Ganz T: Iron in innate immunity: starve the invaders. Curr Opin Immunol 2009, 21:63-67.

11. Murray PJ, Wynn TA: Protective and pathogenic functions of macrophage subsets. Nat Rev Immunol 2011, 11:723-737.

12. Vignery A: Macrophage fusion: the making of osteoclasts and giant cells. J Exp Med 2005, 202:337-340.

13. Bouley DM, Ghori N, Mercer KL, Falkow S, Ramakrishnan L: Dynamic nature of host-pathogen interactions in Mycobacterium marinum granulomas. Infect Immun 2001, 69:7820-7831.

14. Saunders BM, Frank AA, Orme IM, Cooper AM: CD4 is required for the development of a protective granulomatous response to pulmonary tuberculosis. Cell Immunol 2002, 216:65-72.

15. Via LE, Lin PL, Ray SM, Carrillo J, Allen SS, Eum SY, Taylor K, Klein E, Manjunatha U, Gonzales J, Lee EG, Park SK, Raleigh JA, Cho SN, McMurray DN, Flynn JL, Barry CE 3rd: Tuberculous granulomas are hypoxic in guinea pigs, rabbits, and nonhuman primates. Infect Immun 2008, 76:2333-2340.

16. Im JG, Itoh H, Shim YS, Lee JH, Ahn J, Han MC, Noma S: Pulmonary tuberculosis: CT findings-early active disease and sequential change with antituberculous therapy. Radiology 1993, 186:653-660.

17. Poey C, Verhaegen F, Giron J, Lavayssiere J, Fajadet P, Duparc B: High resolution chest $C T$ in tuberculosis: evolutive patterns and signs of activity. J Comput Assist Tomogr 1997, 21:601-607.

18. Kaplan G, Post FA, Moreira AL, Wainwright H, Kreiswirth BN, Tanverdi M, Mathema B, Ramaswamy SV, Walther G, Steyn LM, Barry CE 3rd, Bekker LG: Mycobacterium tuberculosis growth at the cavity surface: $a$ microenvironment with failed immunity. Infect Immun 2003, 71:7099-7108

19. Ulrichs T, Kosmiadi GA, Trusov V, Jorg S, Pradl L, Titukhina M, Mishenko V, Gushina N, Kaufmann SH: Human tuberculous granulomas induce peripheral lymphoid follicle-like structures to orchestrate local host defence in the lung. J Pathol 2004, 204:217-228.

20. Puissegur MP, Botanch C, Duteyrat JL, Delsol G, Caratero C, Altare F: An in vitro dual model of mycobacterial granulomas to investigate the molecular interactions between mycobacteria and human host cells. Cell Microbiol 2004, 6:423-433.

21. Chambers TJ: Fusion of hamster macrophages induced by lectins. J Pathol 1977, 123:53-61.

22. DeFife KM, Jenney CR, MCNally AK, Colton E, Anderson JM: Interleukin-13 induces human monocyte/macrophage fusion and macrophage mannose receptor expression. J Immunol 1997, 158:3385-3390.

23. Enelow Rl, Sullivan GW, Carper HT, Mandell GL: Induction of multinucleated giant cell formation from in vitro culture of human monocytes with interleukin-3 and interferon-gamma: comparison with other stimulating factors. Am J Respir Cell Mol Biol 1992, 6:57-62.

24. Kreipe H, Radzun HJ, Rudolph P, Barth J, Hansmann ML, Heidorn K, Parwaresch MR: Multinucleated giant cells generated in vitro. Terminally differentiated macrophages with down-regulated c-fms expression. Am J Pathol 1988, 130:232-243.

25. Lazarus D, Yamin M, McCarthy K, Schneeberger EE, Kradin R: Anti-RMA, a murine monoclonal antibody, activates rat macrophages: II. Induction of DNA synthesis and formation of multinucleated giant cells. Am J Respir Cell Mol Biol 1990, 3:103-111. 
26. McInnes A, Rennick DM: Interleukin 4 induces cultured monocytes/ macrophages to form giant multinucleated cells. J Exp Med 1988, 167:598-611.

27. Orentas RJ, Reinlib L, Hildreth JE: Anti-class II MHC antibody induces multinucleated giant cell formation from peripheral blood monocytes. J Leukoc Biol 1992, 51:199-209.

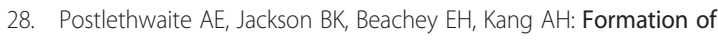
multinucleated giant cells from human monocyte precursors. Mediation by a soluble protein from antigen-and mitogen-stimulated lymphocytes. J Exp Med 1982, 155:168-178.

29. Sone S, Bucana C, Hoyer LC, Fidler IJ: Kinetics and ultrastructural studies of the induction of rat alveolar macrophage fusion by mediators released from mitogen-stimulated lymphocytes. Am J Pathol 1981, 103:234-246.

30. Tabata N, Ito M, Shimokata K, Suga S, Ohgimoto S, Tsurudome M, Kawano M, Matsumura $H$, Komada H, Nishio M, Ito $Y$ : Expression of fusion regulatory proteins (FRPs) on human peripheral blood monocytes. Induction of homotypic cell aggregation and formation of multinucleated giant cells by anti-FRP-1 monoclonal antibodies. J Immunol 1994, 153:3256-3266.

31. Takashima T, Ohnishi K, Tsuyuguchi I, Kishimoto S: Differential regulation of formation of multinucleated giant cells from concanavalin A-stimulated human blood monocytes by IFN-gamma and IL-4. J Immunol 1993, 150:3002-3010.

32. Weinberg JB, Hobbs MM, Misukonis MA: Recombinant human gammainterferon induces human monocyte polykaryon formation. Proc Natl Acad Sci U S A 1984, 81:4554-4557.

33. Chambers TJ: Multinucleate giant cells. J Pathol 1978, 126:125-148.

34. Most J, Neumayer HP, Dierich MP: Cytokine-induced generation of multinucleated giant cells in vitro requires interferon-gamma and expression of LFA-1. Eur J Immunol 1990, 20:1661-1667.

35. Kyriakides TR, Foster MJ, Keeney GE, Tsai A, Giachelli CM, Clark-Lewis I, Rollins BJ, Bornstein P: The CC chemokine ligand, CCL2/MCP1, participates in macrophage fusion and foreign body giant cell formation. Am J Pathol 2004, 165:2157-2166.

36. Yagi M, Miyamoto T, Sawatani Y, Iwamoto K, Hosogane N, Fujita N, Morita K, Ninomiya K, Suzuki T, Miyamoto K, Oike Y, Takeya M, Toyama Y, Suda T: DCSTAMP is essential for cell-cell fusion in osteoclasts and foreign body giant cells. J Exp Med 2005, 202:345-351.

37. Helming L, Gordon S: Molecular mediators of macrophage fusion. Trends Cell Biol 2009, 19:514-522.

38. Jay SM, Skokos E, Laiwalla F, Krady MM, Kyriakides TR: Foreign body giant cell formation is preceded by lamellipodia formation and can be attenuated by inhibition of Rac1 activation. Am J Pathol 2007, 171:632-640.

39. Helming L, Tomasello E, Kyriakides TR, Martinez FO, Takai T, Gordon S, Vivier E: Essential role of DAP12 signaling in macrophage programming into a fusion-competent state. Sci Signal 2008, 1:ra11.

40. Helming L, Winter J, Gordon S: The scavenger receptor CD36 plays a role in cytokine-induced macrophage fusion. J Cell Sci 2009, 122:453-459.

41. MacLauchlan S, Skokos EA, Meznarich N, Zhu DH, Raoof S, Shipley JM, Senior RM, Bornstein P, Kyriakides TR: Macrophage fusion, giant cell formation, and the foreign body response require matrix metalloproteinase 9. J Leukoc Biol 2009, 85:617-626.

42. Van den Bossche J, Bogaert P, Van Hengel J, Guerin CJ, Berx G, Movahedi K, Van den Bergh R, Pereira-Fernandes A, Geuns JM, Pircher H, Dorny P, Grooten J, De Baetselier P, Van Ginderachter JA: Alternatively activated macrophages engage in homotypic and heterotypic interactions through IL-4 and polyamine-induced E-cadherin/catenin complexes. Blood 2009, 114:4664-4674.

43. Yu M, Qi X, Moreno JL, Farber DL, Keegan AD: NF-kappaB signaling participates in both RANKL- and IL-4-induced macrophage fusion: receptor cross-talk leads to alterations in NF-kappaB pathways. J Immunol 2011, 187:1797-1806.

44. French CT, Toesca IJ, Wu TH, Teslaa T, Beaty SM, Wong W, Liu M, Schroder I, Chiou PY, Teitell MA, Miller JF: Dissection of the Burkholderia intracellular life cycle using a photothermal nanoblade. Proc Natl Acad Sci U S A 2011, 108:12095-12100.

45. Horton RE, Grant GD, Matthews B, Batzloff M, Owen SJ, Kyan S, Flegg CP, Clark AM, Ulett GC, Morrison N, Peak IR, Beacham IR: Quorum sensing negatively regulates multinucleate cell formation during intracellular growth of Burkholderia pseudomallei in macrophage-like cells. PLOS One 2013, 8:e63394.
46. Kespichayawattana W, Rattanachetkul S, Wanun T, Utaisincharoen P, Sirisinha S: Burkholderia pseudomallei induces cell fusion and actin-associated membrane protrusion: a possible mechanism for cell-tocell spreading. Infect Immun 2000, 68:5377-5384.

47. Wong KT, Puthucheary SD, Vadivelu J: The histopathology of human melioidosis. Histopathology 1995, 26:51-55.

48. Boddey JA, Day CJ, Flegg CP, Ulrich RL, Stephens SR, Beacham IR, Morrison $N A$, Peak IR: The bacterial gene IfpA influences the potent induction of calcitonin receptor and osteoclast-related genes in Burkholderia pseudomallei-induced TRAP-positive multinucleated giant cells. Cell Microbiol 2007, 9:514-531.

49. Brett PJ, Burtnick MN, Su H, Nair V, Gherardini FC: iNOS activity is critical for the clearance of Burkholderia mallei from infected RAW 264.7 murine macrophages. Cell Microbiol 2008, 10:487-498.

50. Burtnick MN, Brett PJ, Nair V, Warawa JM, Woods DE, Gherardini FC: Burkholderia pseudomallei type III secretion system mutants exhibit delayed vacuolar escape phenotypes in RAW 264.7 murine macrophages. Infect Immun 2008, 76:2991-3000.

51. Harley VS, Dance DA, Drasar BS, Tovey G: Effects of Burkholderia pseudomallei and other Burkholderia species on eukaryotic cells in tissue culture. Microbios 1998, 96:71-93.

52. Pilatz S, Breitbach K, Hein N, Fehlhaber B, Schulze J, Brenneke B, Eberl L, Steinmetz I: Identification of Burkholderia pseudomallei genes required for the intracellular life cycle and in vivo virulence. Infect Immun 2006, 74:3576-3586.

53. Suparak S, Kespichayawattana W, Haque A, Easton A, Damnin S, Lertmemongkolchai G, Bancroft GJ, Korbsrisate S: Multinucleated giant cell formation and apoptosis in infected host cells is mediated by Burkholderia pseudomallei type III secretion protein BipB. J Bacteriol 2005, 187:6556-6560.

54. Whitmore A: An Account of a Glanders-like Disease occurring in Rangoon. J Hyg 1913, 13:1-34 31

55. Schell MA, Ulrich RL, Ribot WJ, Brueggemann EE, Hines HB, Chen D, Lipscomb L, Kim HS, Mrazek J, Nierman WC, Deshazer D: Type VI secretion is a major virulence determinant in Burkholderia mallei. Mol Microbiol 2007, 64:1466-1485.

56. Shalom G, Shaw JG, Thomas MS: In vivo expression technology identifies a type VI secretion system locus in Burkholderia pseudomallei that is induced upon invasion of macrophages. Microbiology 2007, 153:2689-2699.

57. Muangsombut $V$, Suparak S, Pumirat P, Damnin S, Vattanaviboon P, Thongboonkerd $V$, Korbsrisate S: Inactivation of Burkholderia pseudomallei bsaQ results in decreased invasion efficiency and delayed escape of bacteria from endocytic vesicles. Arch Microbio/ 2008, 190:623-631.

58. Burtnick MN, Brett PJ, Harding SV, Ngugi SA, Ribot WJ, Chantratita N, Scorpio A, Milne TS, Dean RE, Fritz DL, Peacock SJ, Prior JL, Atkins TP, Deshazer D: The cluster 1 type $\mathrm{VI}$ secretion system is a major virulence determinant in Burkholderia pseudomallei. Infect Immun 2011, 79:1512-1525.

59. Utaisincharoen P, Arjcharoen S, Limposuwan K, Tungpradabkul S, Sirisinha S: Burkholderia pseudomallei RpoS regulates multinucleated giant cell formation and inducible nitric oxide synthase expression in mouse macrophage cell line (RAW 264.7). Microb Pathog 2006, 40:184-189.

60. Toesca IJ, French CT, Miller JF: The T6SS-5 VgrG spike protein mediates membrane fusion during intercellular spread by pseudomallei-group Burkholderia species. Infect Immun 2014, 82:1436-1444.

61. Bullen A: Microscopic imaging techniques for drug discovery. Nat Rev Drug Discov 2008, 7:54-67.

62. Christophe T, Jackson M, Jeon HK, Fenistein D, Contreras-Dominguez M, Kim J, Genovesio A, Carralot JP, Ewann F, Kim EH, Lee SY, Kang S, Seo MJ, Park EJ, Skovierova H, Pham H, Riccardi G, Nam JY, Marsollier L, Kempf M, Joly-Guillou ML, Oh T, Shin WK, No Z, Nehrbass U, Brosch R, Cole ST, Brodin P: High content screening identifies decaprenyl-phosphoribose 2' epimerase as a target for intracellular antimycobacterial inhibitors. PLOS Pathog 2009, 5: e1000645.

63. Gurumurthy RK, Maurer AP, Machuy N, Hess S, Pleissner KP, Schuchhardt J, Rudel T, Meyer TF: A loss-of-function screen reveals Ras- and Rafindependent MEK-ERK signaling during Chlamydia trachomatis infection. Sci Signal 2010, 3:ra21.

64. Lang P, Yeow K, Nichols A, Scheer A: Cellular imaging in drug discovery. Nat Rev Drug Discov 2006, 5:343-356.

65. Low J, Stancato L, Lee J, Sutherland JJ: Prioritizing hits from phenotypic high-content screens. Curr Opin Drug Discov Devel 2008, 11:338-345. 
66. Misselwitz B, Dilling S, Vonaesch P, Sacher R, Snijder B, Schlumberger M, Rout S, Stark M, Von Mering C, Pelkmans L, Hardt WD: RNAi screen of Salmonella invasion shows role of COPI in membrane targeting of cholesterol and Cdc42. Mol Syst Biol 2011, 7:474.

67. Perlman ZE, Slack MD, Feng Y, Mitchison TJ, Wu LF, Altschuler SJ: Multidimensional drug profiling by automated microscopy. Science 2004, 306:1194-1198.

68. Tanaka M, Bateman R, Rauh D, Vaisberg E, Ramachandani S, Zhang C, Hansen KC, Burlingame AL, Trautman JK, Shokat KM, Adams CL: An unbiased cell morphology-based screen for new, biologically active small molecules. PLOS Biol 2005, 3:e128.

69. Young DW, Bender A, Hoyt J, McWhinnie E, Chirn GW, Tao CY, Tallarico JA, Labow M, Jenkins JL, Mitchison TJ, Feng Y: Integrating high-content screening and ligand-target prediction to identify mechanism of action. Nat Chem Biol 2008, 4:59-68.

70. Warawa J, Woods DE: Type III secretion system cluster 3 is required for maximal virulence of Burkholderia pseudomallei in a hamster infection model. FEMS Microbiol Lett 2005, 242:101-108.

71. Bierne $\mathrm{H}$, Hamon $\mathrm{M}$, Cossart P: Epigenetics and bacterial infections. Cold Spring Harbor Perspectives in Medicine 2012, 2:a010272.

72. Heine HS, England MJ, Waag DM, Byrne WR: In vitro antibiotic susceptibilities of Burkholderia mallei (causative agent of glanders) determined by broth microdilution and E-test. Antimicrob Agents Chemother 2001, 45:2119-2121.

73. Wilson K: Preparation of genomic DNA from bacteria. Curr Protoc Mol Biol 2001, 00:2.4.1-2.4.5.

74. Hamad MA, Zajdowicz SL, Holmes RK, Voskuil Ml: An allelic exchange system for compliant genetic manipulation of the select agents Burkholderia pseudomallei and Burkholderia mallei. Gene 2009, 430:123-131.

75. DeShazer D, Brett PJ, Carlyon R, Woods DE: Mutagenesis of Burkholderia pseudomallei with Tn5-OT182: isolation of motility mutants and molecular characterization of the flagellin structural gene. J Bacteriol 1997, 179:2116-2125.

76. Ulrich RL, Amemiya K, Waag DM, Roy CJ, DeShazer D: Aerogenic vaccination with a Burkholderia mallei auxotroph protects against aerosol-initiated glanders in mice. Vaccine 2005, 23:1986-1992

doi:10.1186/1471-2180-14-98

Cite this article as: Pegoraro et al: A high-content imaging assay for the quantification of the Burkholderia pseudomallei induced multinucleated giant cell (MNGC) phenotype in murine macrophages. BMC Microbiology 2014 14:98.

\section{Submit your next manuscript to BioMed Central and take full advantage of:}

- Convenient online submission

- Thorough peer review

- No space constraints or color figure charges

- Immediate publication on acceptance

- Inclusion in PubMed, CAS, Scopus and Google Scholar

- Research which is freely available for redistribution

Submit your manuscript at www.biomedcentral.com/submit
(O) Biomed Central 